\title{
A importância da formação continuada: $O$ aprimoramento profissional frente aos desafios do séc. XXI
}

The importance of continuing education: Professional improvement facing the challenges of the $21^{\text {st }}$ century

La importância de formacion continua: La superación professional ante los retos del siglo. XXI

Recebido: 07/07/2021 | Revisado: 10/07/2021 | Aceito: 14/07/2021 | Publicado: 24/07/2021

Ana Greyce Lima da Silva de Mesquita

ORCID: https://orcid.org/0000-0002-7057-5067

Universidade Estácio de Sá, Brasil

E-mail: pedagoga.anagreyce@gmail.com

\begin{abstract}
Resumo
Este artigo apresenta resultados adquiridos por meio de estudos realizados sobre as práticas de uma educação continuada para os professores da atualidade, sendo esse o foco principal. Este trabalho teve como foco mostrar aspectos nas propostas de formação, e também refletir sobre a significativa importância da formação continuada e as práticas diárias dos educadores da Educação Básica. A metodologia aqui apresentada está fundamentada na pesquisa qualitativa. Apresenta, ainda, estratégias de como os educadores podem trabalhar os conteúdos curriculares por meio das tecnologias e dos jogos. É notório que em sua formação inicial, os educadores não se detém de todos os saberes que são necessários para que se atenda todas as necessidades que os alunos trazem hoje para uma sala de aula, pois o contexto de vida do aluno muda de acordo com cada realidade, e com isso, é necessário que os educadores da atualidade permaneça estudando e se atualizando, realizando uma formação continuada de qualidade a fim de (re)aprender, ou (re)significar suas práticas diárias, buscando aprimorar seus conhecimentos e suas práticas em suas experiências do dia a dia.
\end{abstract}

Palavras-chave: Educação; Educação continuada; Práticas diárias do professor; Ensino.

\begin{abstract}
This article presents results acquired through studies carried out on the practices of continuing education for teachers today, which is the main focus. This work focused on showing aspects of the training proposals, and also reflecting on the significant importance of continuing education and the daily practices of Basic Education educators. The methodology presented here is based on qualitative research. It also presents strategies on how educators can work on curriculum content through technologies and games. It is clear that in their initial training, educators do not hold all the knowledge that is necessary to meet all the needs that students bring to a classroom today, as the context of the student's life changes according to each reality, and with this, it is necessary that today's educators continue to study and update themselves, carrying out quality continuing education in order to (re)learn, or (re)signify their daily practices, seeking to improve their knowledge and practices in your everyday experiences.
\end{abstract}

Keywords: Education; Continuing education; Teacher's daily practices; Teaching.

\section{Resumen}

Este artículo presenta los resultados adquiridos a través de los estudios realizados sobre las prácticas de la educación continua para los docentes en la actualidad, que es el foco principal. Este trabajo se enfocó en mostrar aspectos de las propuestas formativas, y también reflexionar sobre la gran importancia de la educación continua y las prácticas diarias de los educadores de Educación Básica. La metodología que aquí se presenta se basa en una investigación cualitativa. También presenta estrategias sobre cómo los educadores pueden trabajar en el contenido del plan de estudios a través de tecnologías y juegos. Es claro que en su formación inicial, los educadores no poseen todos los conocimientos necesarios para cubrir todas las necesidades que los estudiantes traen hoy a un aula, ya que el contexto de la vida del estudiante cambia según cada realidad, y con ello, Es necesario que los educadores de hoy sigan estudiándose y actualizándose, realizando una formación continua de calidad para (re) aprender, o (re) significar sus prácticas diarias, buscando mejorar sus conocimientos y prácticas en sus vivencias cotidianas.

Palabras clave: Educación; Educación continua; Prácticas diarias del maestro; Enseñanza. 


\section{Introdução}

Investir em formação continuada é um ponto estratégico, tendo em vista que é um direito dos professores, sendo estabelecido essa garantia em diversos documentos, entre eles destacamos a Constituição Federal e a Lei de Diretrizes e Bases.

O professor precisa de uma atualização constante. Quando falamos em formação continuada estamos nos referindo a um processo continuo, um processo que valorize a experiência docente e que aconteça centralmente dentro do espaço escolar, não sendo impossível de ser realizado também em um ambiente extraescolar.

Quando uma rede valoriza e pratica a formação continuada especialmente no contexto escolar das instituições, a tendência é que qualidade da educação em todas as suas modalidades melhore. Quando a formação continuada acontece na escola, ela possibilita que o contexto onde essa formação está inserida seja um elemento para a transformação.

Quando um professor resolve investir em aperfeiçoamento e em novas formas de aprender, além de ser um benefício para si quanto profissional, pois o mesmo terá um alicerce melhor de conhecimentos e informações, esse benefício reflete também em seus alunos, pois eles terão um ensino com mais qualidade e um melhor embasamento teórico, que será construído junto com um professor que se preocupou em oferecer o melhor para os seus alunos e pra o bem da profissão.

No decorrer deste trabalho vamos discutir a importância da formação continuada na vida profissional. Entendendo que essa busca por novos conhecimentos constantes traz inúmeros benefícios não só para o profissional como também para a instituição que ele trabalha.

Neste estudo vamos também relacionar os temas pedagógicos abordados atualmente na formação pedagógica e na formação dos professores tendo como ponto a sua atuação no cotidiano da sala de aula.

Os objetivos específicos desta pesquisa propõem:

- Evidenciar as principais características no aprimoramento profissional constante e sua importância no desenvolvimento do profissional.

- Apresentar o levantamento de alguns benefícios do aprimoramento profissional contínuo que podem ser utilizados no decorrer da vida profissional.

- Investigar como os educadores desenvolvem as suas práticas de formação continuada no cotidiano de seu trabalho e qual importância atribui a essa formação.

\section{Metodologia}

Esta pesquisa é de caráter qualitativo, adotando como procedimento técnico a pesquisa bibliográfica, onde se procurou compreender as habilidades quanto à utilização da formação continuada como ferramenta para o ensino-aprendizagem. Os motivos pelo qual escolhi a pesquisa qualitativa é que nesta pesquisa busco descobrir a importância da formação continuada para a vivência de um bom profissional. Sobre a pesquisa qualitativa Minayo (2001, p. 14) deixa claro a seguinte ideia:

"A pesquisa qualitativa trabalha com o universo de significados, motivos, aspirações, crenças, valores e atitudes, o que corresponde a um espaço mais profundo das relações, dos processos e dos fenômenos que não podem ser reduzidos à operacionalização de variáveis".

De acordo com Denzin e Lincoln (2006), a pesquisa qualitativa envolve uma abordagem interpretativa do mundo, o que significa que seus pesquisadores estudam as coisas em seus cenários naturais, tentando entender os fenômenos em termos dos significados que as pessoas a eles conferem. Acompanhando essa linha de raciocínio, Vieira e Zouain (2005) afirmam que a pesquisa qualitativa atribui importância fundamental aos depoimentos dos atores sociais envolvidos, aos discursos e aos significados transmitidos por eles. Nesse sentido, esse tipo de pesquisa preza pela descrição detalhada dos fenômenos e dos elementos que o envolvem. 
Juntamente a pesquisa qualitativa, foi adotado o procedimento técnico de pesquisa bibliográfica que, foi utilizada para explanar sobre o tema, dar embasamento teórico, e ainda confiabilidade ao assunto abordado e as afirmações feitas ao decorrer do trabalho.

\section{Resultados}

Nos dias atuais é notório que cada vez mais as instituições exigem profissionais altamente qualificados e atualizados. E não podemos mais limitar nossa mente pensando que o diploma de graduação seja o suficiente para nos manter no mercado e qualificados, para um mundo que se atualiza todos os dias.

Nós somos desafiados a mudar constantemente e cada mudança traz seu crescimento, por isso jamais será cedo ou tarde para aprender ou se desenvolver. Enquanto houver oportunidades, haverá espaço para um novo aprendizado.

O termo formação continuado propõe justamente isso, se manter atualizado para acompanhar as constantes mudanças de conceito das nossas áreas de atuação.

A formação continuada tem por excelência aprofundar habilidades, adquirir novos conhecimentos e nos mantermos atualizados. Se queremos crescer profissionalmente precisamos investir tempo buscando conhecimento pois, pois nos ajudará a analisar de forma mais crítica nossa atuação, a repensar processos e criar novas estratégias.

Os resultados aqui apresentados estão embasados em uma pesquisa qualitativa, a pesquisa qualitativa se preocupa com o nível de realidade que não pode ser quantificado, ou seja, ela trabalha com o universo de significados, de motivações, aspirações, crenças, valores e atitudes (Minayo, 2014).

\subsection{Formação continuada e contribuições legais}

É notório que o aprimoramento profissional contínuo é uma exigência da LDB 9394/96. Os professores e educadores necessitam conhecer as leis que regem seus deveres e principalmente seus direitos, para que, possam exigir das autoridades competentes, sejam elas entidades públicas ou particulares.

É de suma importância destacar os deveres docentes no trabalho pedagógico com crianças que deve deixar claro a diferença entre cuidar e educar, permitindo pelo processo da organização do tempo e do espaço, possibilidades para o conhecimento, para a aprendizagem e desenvolvimento infantil. Em relação aos direitos nos embasamos na Lei de Diretrizes e Bases da Educação Nacional - Lei 9.394/96, no Artigo 13, que destaca os docentes incumbir-se-ão de:

I - participar da elaboração da proposta pedagógica do estabelecimento de ensino;

II - elaborar e cumprir plano de trabalho, segundo a proposta pedagógica do estabelecimento de ensino;

III - zelar pela aprendizagem dos alunos;

IV - estabelecer estratégias de recuperação para os alunos de menor rendimento;

V - ministrar os dias letivos e horas-aula estabelecidos, além de participar integralmente dos períodos dedicados ao planejamento, à avaliação e ao desenvolvimento profissional;

VI - colaborar com as atividades de articulação da escola com as famílias e a comunidade (BRASIL, 1996, p. 6)

As reformas que acontecem na educação como um todo, e para a formação dos educadores em especial, estão materializadas nos documentos que legitimam a educação nacional. Dentre estes destacamos: a Lei de diretrizes e Bases que dedica os seus artigos 61 a 65 do Título VI - Dos Profissionais da Educação, trazendo mudanças que são relevantes no contexto da formação dos profissionais da educação, ao evidenciar que a formação se faça em "cursos reconhecidos". O parágrafo único do Art. 61: 
A formação dos profissionais da educação, de modo a atender às especificidades do exercício de suas atividades, bem como aos objetivos das diferentes etapas e modalidades da educação básica, terá como fundamentos:

I - a presença de sólida formação básica, que propicie o conhecimento dos fundamentos científicos e sociais de suas competências de trabalho;

II - a associação entre teorias e práticas, mediante estágios supervisionados e capacitação em serviço;

III - o aproveitamento da formação e experiências anteriores, em instituições de ensino e em outras atividades. (Brasil, 1996)

Conforme a Lei de diretrizes e Bases explica, o professor é extremamente relevante a fim de que a qualidade do ensino seja cumprida e aperfeiçoada constantemente. Sua contribuição no percurso do dia a dia escolar, além contexto da sala de aula, é de extrema importância para seu crescimento pessoal e profissional, principalmente quando o item I ressalta a sua participação na elaboração da proposta pedagógica da escola. Infelizmente por muitas vezes o professor não consegue se dedicar aos seus direitos como gostaria em virtude da pressão diária no seu trabalho.

Mediante à toda a cobrança os professores não podem deixar que a qualidade diária do ensino sofra com isso sendo preciso lutar frequentemente para conseguir se estabelecer como um profissional de qualidade e capaz. Freire (2009, p. 68) destaca que "[...] não é parar de lutar, mas, reconhecendo-se que a luta é uma categoria histórica, reinventar a forma também histórica de lutar".

Dessa forma, os professores precisam refletir sobre a maneira ideal de lutar pela categoria. Os gestores devem apoiar com os educadores. A formação continuada é uma das formas de valorização do profissional, em que o gestor pode e deve colaborar com o professor levando-o a refletir sobre sua posição, bem como dar suporte pedagógico e administrativo para o seu aperfeiçoamento. Sobre esse o que discorre a LDB esclarece:

Art. 67. Os sistemas de ensino promoverão a valorização dos profissionais da educação, assegurando-lhes, inclusive nos termos dos estatutos e dos planos de carreira do magistério público:

I - ingresso exclusivamente por concurso público de provas e títulos;

II - aperfeiçoamento profissional continuado, inclusive com licenciamento periódico remunerado para esse fim;

III - piso salarial profissional;

IV - progressão funcional baseada na titulação ou habilitação, e na avaliação do desempenho;

V - período reservado a estudos, planejamento e avaliação, incluído na carga de trabalho;

VI - condições adequadas de trabalho (Brasil, 1996, p. 21).

Destacamos também outro documento de suma importância que são as Diretrizes. Ao estabelecerem um novo perfil docente, que está centrado no desenvolvimento de competências, em cursos que enaltecem a prática em detrimento da teoria, ao se colocarem a favor da noção de "simetria invertida" o que, entre outros aspectos

[...] evidencia a necessidade de que o futuro professor experiencie, como aluno, durante todo o processo de formação, as atitudes, modelos didáticos, capacidades e modos de organização que se pretende venham a ser concretizados nas suas práticas pedagógicas [...]. (Brasil, 2001, p.30-31)

Outro documento em destaque é o PNE (Plano Nacional de Educação 2014-2024), com foco em suas metas 15 e 16 , por tratarem da questão da formação inicial e continuada de professores. O texto corrobora com a formação docente que 
"valoriza a experiência na prática", como expresso na estratégia, retomando a lógica de valorização dos "saberes da experiência" em detrimento de conhecimentos da área de atuação profissional. O processo de aperfeiçoamento profissional presente mais largamente encontra-se organizadas na primeira em estratégias, buscando

Garantir, em regime de colaboração entre a União, os Estados, o Distrito Federal e os Municípios, no prazo de 1 ano de vigência deste PNE, política nacional de formação dos profissionais da educação de que tratam os incisos I, II e III do caput do art. 61 da Lei $\mathrm{n}^{\circ}$ 9.394, de 20 de dezembro de 1996, assegurado que todos os professores e as professoras da educação básica possuam formação específica de nível superior, obtida em curso de licenciatura na área de conhecimento em que atuam. (Brasil, 2014)

A estratégia 16.1 do Plano Nacional de Educação prevê o dimensionamento da demanda por formação continuada em regime de colaboração (Federal, Estadual e Municipal), todavia, nada é dito sobre as formas e em que condições se fará a formação continuada. É de suma importância destacar que, ao longo do documento como um todo, a iniciativa privada está fortemente presente. $\mathrm{O}$ discurso do MEC torna grandiosa a educação de professores, conferindo ênfase ao aprimoramento profissional contínuo:

1. no Parecer $n^{\circ}$ CNE/CP 009/2001 que fundamenta as Diretrizes, a formação continuada aparece como atendimento “[...] a formação (que) deva ser complementada ao longo da vida [...]" (p.9); ao endossar os artigos da LDB que fazem referência à "relação entre teoria e prática" e no "aproveitamento da experiência anterior", ao construir aprendizagens significativas junto aos futuros alunos; e, oferta de "programas de educação continuada" (p.14). Ao finalizar traz que "É ainda no momento de definição da estrutura institucional e curricular do curso que caberá a concepção de um sistema de oferta de formação continuada que propicie oportunidade de retorno planejado e sistemático dos professores às agências formadoras [...]” (Brasil, 2001 p.58);

2. nas Metas 1, 3, 4, 5, 7, 10 onde a formação continuada está presente quer promovendo a formação, incentivando práticas pedagógicas estruturadas a partir da relação teoria/prática, quer repensando currículos, ampliação de vagas e outros.

Além dos documentos citados, que conformam a educação nacional, merece também ressalta a Rede Nacional de Formação Continuada de Professores (Brasil, 2004), “[...] criada em 2004, com o objetivo de contribuir para a melhoria da formação dos professores e alunos. O público-alvo prioritário da Rede são professores de Educação Básica dos sistemas públicos de educação [...]".

Com a necessidade de oferta de educação de qualidade aos futuros professores os programas de Formação Continuada apresentados no site do MEC: Formação no Pacto Nacional pela Alfabetização na Idade Certa; ProInfantil; Plano Nacional de Formação de Professores da Educação Básica; Proinfo Integrado; e-Proinfo; Pró- -letramento; Gestar II; Rede Nacional de Formação Continuada de Professores. Sobre os diversos Programas oferecidos, Gatti (2008) nos ajuda a elucidar que:

[...] muitas das iniciativas públicas de formação continuada no setor educacional adquiriram, então, a feição de programas compensatórios e não propriamente de atualização e aprofundamento em avanços do conhecimento, sendo realizados com a finalidade de suprir aspectos da má-formação anterior, alterando o propósito inicial dessa educação - 
posto nas discussões internacionais, que seria o aprimoramento dos profissionais nos avanços, renovações e inovações de suas áreas [...]. (Gatti, 2008, p. 58)

Segundo a ideologia das políticas de formação de professores, Evangelista e Shiroma (2004, p.535) levantam a hipótese de que

[...] a política de profissionalização de professores e gestores, nos moldes em que vem sendo implantada, tem por objetivo não o aumento da qualificação do quadro do magistério, mas, sim, a sua desintelectualização para, desse modo, torná-los pragmáticos, diminuindo-lhes a capacidade de intervenção consciente [...].

\subsection{A formação continuada, fatores positivos e dificuldades enfrentadas}

A formação continuada nos dias atuais tem sido um assunto de extrema relevância no convivo escolar, para começamos a descore sobre a assunto façamos menção sobre um pequeno texto de Peter Brook que diz:

Nunca acreditei em verdades únicas. Nem nas minhas, nem nas dos outros. Acredito que todas as escolas, todas as teorias podem ser úteis em algum lugar, num dado momento. Mas descobri que é impossível viver sem uma apaixonada e absoluta identificação com um ponto de vista. No entanto, à medida que o tempo passa, e nós mudamos, e o mundo se modifica, os alvos variam e o ponto de vista se desloca. Num retrospecto de muitos anos de ensaios publicados e ideias proferidas em vários lugares, em tantas ocasiões diferentes, uma coisa me impressiona por sua consistência. Para que um ponto de vista seja útil, temos que assumi-lo totalmente e defendê-lo até a morte. Mas, ao mesmo tempo, uma voz interior nos sussurra: "Não o leve muito a sério. Mantenha-o firmemente, abandone-o sem constrangimento." (Brook, 1995)

Nessa perspectiva podemos entender que não existem verdades absolutas, todavia tudo que aprendemos podemos pôr em prática em algum lugar e em algum momento. Segundo Zabala $(2018$, p.13) "um dos objetivos de qualquer bom profissional consiste em ser cada vez mais competente em seu ofício".

Melhores professores, formam melhores alunos, pode até parecer clichê, mas é um fato. Os estudos de Aaronson, Barrow, Sander (2007), Rivikin, Hanushek e Kain (2005) e Rockoff (2004) sobre o Impacto adicional no aprendizado de alunos expostos aos $20 \%$ melhores professores, confirmam que estudantes com bons profissionais, tem rendimento superior de $47 \%$ e $70 \%$ a mais do que aprenderiam com docentes menos preparados.

Conforme Libâneo (1998), a formação continuada leva os professores a um desempenho reflexivo, haja vista que, depois do desenvolvimento da sua prática, estes poderão reformular as atividades para uma próxima ocasião, repensando as questões positivas e negativas acontecidos durante o desenrolar das aulas, procurando melhorias nas atividades e exercícios que não se apresentaram eficientes e eficazes.

Para melhorar a aprendizagem o aprimoramento dos educadores é a iniciativa mais acessível e eficiente. Consoante especialistas uma característica dos programas de formação continuada é seu caráter compensatório, segundo pesquisas:

[...] as intensificações ocorreram devido à universalização do ensino e da necessidade de ampliação do quadro de docentes, obtendo a formação continuada um caráter compensatório e de enfrentamento do insucesso escolar com uma abordagem fortemente individualista. (Fundação Victor Civita, 2011 apud Santos \& Silva, 2012, p. 84): 
Além desses fatores, em boa parte dos casos a padronização dos cursos tendem a desconsiderar as necessidades especificas de cada escola. O que temos hoje no Brasil é uma formação continuada muito pautada pela oferta, então o professor quando vai em busca de um aprimoramento, ele vai olhar para os institutos de formação de professores, de secretárias, vai ver o que está sendo oferecido e vai escolher como se fosse um "cardápio", o que deveria ser levado como prioridade acaba sendo levado por um simples impulso de escolha.

O pouco tempo que é denominado de "trabalho coletivo" na escola, ele está sendo ocupado por demandas externas. Então, a formação local que é feita com a mediação dos coordenadores pedagógicos, ou de outros professores ela também acaba perdendo seu potencial criativo e de apoio ao projeto pedagógico da escola na medida em que também esse espaço vem sendo pautado desde o exterior. Zechner contribui com um pensamento:

Mesmo quando a "reflexão" é utilizada como um veículo para o desenvolvimento real dos professores, ela é vista como um fim em si mesmo, desconectado de questões mais amplas sobre a educação em sociedades democráticas. Geralmente, afirma-se ou assume-se que se professores refletirem sobre o que fazem, eles necessariamente serão melhores profissionais. (2008, p. 545)

Os obstáculos a serem superados para melhorarem a qualidade da formação em serviço, segundo estudo divulgado pela pesquisa em São Paulo pelo Instituto Ayrton Senna (IAS) são:

* Carência de incentivos formais; Só $2 \%$ dos professores brasileiros participam de atividades práticas de formação e treinamento durante sua carreira, consideradas pelos especialistas como as mais eficazes.

* $\quad$ Escassez de tempo por parte dos professores;

* Lacunas e baixa aplicabilidade dos conteúdos das ações oferecidas;

* Preferências por ações de curto prazo e alta visibilidade;

* Alta rotatividade do corpo docente;

Para ir contra esses fatores que acabam dificultando a formação continuada dos professores, a escola e os gestores precisam investir cada vez mais em recursos e estratégias que ajudem o professor nessa qualificação.

O professor é um pesquisador, ele é um ser reflexivo por natureza. Segundo Lüdke (2001, p. 80), no trabalho de Stenhouse (1975) o professor pesquisador foi colocado em destaque como o profissional que, tal como um artista, busca as melhores maneiras de atingir os alunos no processo de ensino e aprendizagem e, utilizando diferentes materiais, procura soluções mais adequadas à sua criação.

O educador só vai conseguir se aperfeiçoar em sua prática quando ele conseguir fazer aquela tradição entre prática e teoria, teoria e prática. A formação continuada ela é muito importante, pois ela é uma formação que dá um suporte a mais ao profissional. Menga Lüdke (2001, p.5), tratando sobre o tema da formação de professores, afirma que:

O desenvolvimento profissional só poderá acontecer no contexto de um processo que articule intimamente teoria e prática educativas, num diálogo estreito com os sujeitos e as circunstâncias concretas de cada processo educacional e tendo em vista o aprimoramento da sociedade no seu conjunto.

Para a utilização de tecnologias a formação continuada tem uma importância reforçada, pois com a tecnologia o fazer é muito importante, o experimentar é muito importante, além de proporcionar um ambiente pedagógico diferente do tradicional, no qual o aluno tem de tornar-se ativo no processo de ensino-aprendizagem (Nascimento, 2020) 
Se o professor tivesse o tempo para formação na sua rotina de trabalho, essa pesquisa com as tecnologias, até mesmo no dia-a-dia com o aluno, na classe e com o grupo escolar, ele teria um avanço mais sistemático e se sentiria mais seguro para uso das tecnologias.

É notório que, há muitas dúvidas entre os professores no decorrer das aulas sobre a melhor forma de lidar com as novas tecnologias. Segundo Lévy (1996), a era atual das tecnologias da informação e comunicação estabelece uma nova forma de pensar sobre o mundo que vem substituindo princípios, valores, processos, produtos e instrumentos que mediam a ação do homem com o meio dentre tantos fatores temos alguns professores que adotam como métodos a proibição pura e simples do celular dentro de sala de aula, por exemplo e outros argumentam que é melhor essa tecnologia para auxiliar o processo de ensino-aprendizagem dos alunos.

Os professores devem ter consciência de que, a tecnologia é capaz de ajudar o professor, mas não o substitui. Pode ajudá-lo a ensinar melhor e com melhor qualidade, mas não reduzirá o esforço necessário na sala de aula. Pelo contrário, creio que devemos aumentar o número de professores. (Hawkins, 1995, p.61)

Há momentos em que disciplinar o foco e fortalecer a concentração é realmente a coisa mais importante há se fazer. Ao analisar o uso da tecnologia na educação Kearsley (1993) considera que a tecnologia pode ajudar o professor a obter resultados melhores por conseguir amplificar as habilidades humanas, mas, para que isso ocorra é necessário que o professor possua habilidades e competências adequadas.

A formação continuada de professores se torna uma das mais importantes estratégias para a contribuição com o processo de formação que oportuniza aprendizados referentes as metodologias educacionais, bem como aos procedimentos que serão obtidos com as práticas desenvolvidas em sala de aula e em sociedade. Mediante esse processo de formação, os professores estão sempre buscando oportunidades de novas estratégias de ensino. Do ponto de vista de Wengzynski e Tozetto (2012, p. 4) O professor enquanto sujeito do contexto educativo, cujas ações são tomadas de maneira intencional é formado em consonância com os objetivos postos pela sociedade e estas demandam as práticas as quais esses professores serão portadores. Uma realidade a ser transformada acontece por meio das ações que os docentes realizam em educação manifestando-se e transformando o que acontece a sua volta.

Diante do exposto com a utilização consciente desse recurso o professor pode ampliar a dinâmica de sua aula, e não as usar como um passatempo, mas sim com uma fundamentação da aula aliada a um planejamento. Incrementando nas suas aulas, e despertado nos alunos a vontade de aprender de forma cada vez mais prazerosa e significativa, contribuindo assim para a formação de um cidadão completo em todas as áreas. E com uma formação continuada e uma orientação adequada os benefícios serão significativos.

\section{Conclusão}

Consoante com as análises feitas no decorrer deste trabalho podemos perceber que as políticas sociais relacionadas à área da educação, constata-se que o aprimoramento profissional contínuo para os educadores da atualidade constitui-se em uma das mais complexas; envolve uma área de inúmeros fatores que devem ser considerados com bastante cautela: o conhecimento, o trabalho coletivo, a realidade dos alunos, a história e rotina da escola, a sociedade, o contexto histórico que as envolve, dentre tantos outros.

De certa forma pode ser concebida para atender "modismos" ou como fonte de "acúmulo" de certos cursos. Deve se constituir em um trabalho de constante aperfeiçoamento para a prática do educador devendo atingir as necessidades e possibilidades reais da escola e dos alunos. 
Percebe-se que no decorrer das atividades escolares, de modo geral, devem ocorrer a partir de interações e diálogo entre professores e alunos, sendo estas atividades quase que impossíveis de serem preparadas somente pelos professores, sem que sejam levados em conta a própria aprendizagem e as bases que o aluno já possui em sua bagagem, e a realização de poder finalizar as atividades com êxito por ambas as partes.

Desse modo, a proposta deste de trabalho foi de cunho desafiador, pois foram longas pesquisas para poder entender quais são as causas e os erros que vem sendo cometidos em classe e como a formação continuada traria bases para solucionar a maioria desses problemas.

Tendo em vista portanto, que são muitas as variáveis que influenciam a definição da identidade profissional do educador, diante do exposto devemos considerar as questões da autonomia na realização das atividades dos educadores em classe e da relação que se constrói dos grupos em que se envolve.

Tendo em vista que um profissional que se atualiza constantemente nunca ficará para trás no conhecimento, e terá sempre o melhor para oferecer para os seus alunos, sabendo que o conhecimento evolui de tal forma dia a pós dia.

De sugestão para os próximos trabalhos, acredito ser de extrema importância a busca de novas tecnologias educacionais e sua utilização frente aos desafios enfrentados neste século e de que maneira a formação continuada pode ser desenvolvida mediante ao novo cenário.

\section{Referências}

Brasil. (1996). Lei n ${ }^{9} 9394$, de 20 de dezembro de 1996. Estabelece as diretrizes e bases da educação nacional. Diário Oficial da União

Brasil. (2014) Lei n ${ }^{\circ} 13.005$, de 25 de junho de 2014. Aprova o Plano Nacional de Educação - PNE e dá outras providências. Diário Oficial [da] República Federativa do Brasil.

Brasil. (2004). Rede Nacional de Formação Continuada de Professores da Educação Básica: orientações gerais. http://www.scielo.br/scielo.php?script=sci_nl inks\&pid=S01013262201500010001500004\&lng=en

Brasil. (1998) Ministério da Educação. Secretaria de Educação Fundamental. Referencial curricular nacional para a educação infantil.

Brook, P.(1995). O Ponto de Mudança Rio de Janeiro: Civilização Brasileira

Denzin, N. K. \& Lincoln, Y. S. (2006) Introdução: a disciplina e a prática da pesquisa qualitativa.

Evangelista, O. \& Shiroma, E. O. (2004). A colonização da utopia nos discursos sobre profissionalização docente. Perspectiva. Florianópolis. 22(2), 525-45

Freire P. (2009). Pedagogia da Autonomia: Saberes Necessários À Prática Educativa

Gatti, B. A. (2008) Análise da política públicas para formação continuada no Brasil, na última década. Revista Brasileira de Educação

Hawkins, J (1995) O uso de novas tecnologias na educação. Revista TB

Kearsley, G. (1993) Education technology: does it work? ED-Tech Review, Spring/Summer

Libâneo, J. C. (1998) Adeus professor, adeus professora? novas exigências educacionais e profissão docente.

Ludke, M. (2001). O professor e a pesquisa. Papirus

Ludke, M. (2001) O professor, seu saber e sua pesquisa. Educação \& Sociedade

Minayo, M. C. de S. (2014). O desafio do conhecimento: pesquisa qualitativa em saúde.

Minayo, M. C. S. (2001). Pesquisa social: teoria, método e criatividade.

Nascimento, F. G. M. \& Rosa, J. V. A. (2020). Princípio da sala de aula invertida: uma ferramenta para o ensino de química em tempos de pandemia. Brazilian Journal of Development, 6(6), 38513-38525.

Silva, R. O. (2011) da.Políticas de formação continuada do professor formador em um centro de formação e atualização dos profissionais da educação básica.

Vieira, M. M. F. \& Zouain, D. M. (2005) Pesquisa qualitativa em administração: teoria e prática.

Wengzynki, D. C \& Tozetto, S. S. (2012) A formação continuada face as suas contribuições para a docência.

Zabala, A.(2018). A prática educativa: como ensinar. Artmed

Zeichner, K. M. (2008) Uma análise crítica sobre a "reflexão" como conceito estruturante na formação docente. Educação e Sociedade. 